\title{
Dam Site Selection Using Remote Sensing Techniques and Geographical Information System to Control Flood Events in Tabuk City
}

\section{Eyad Abushandi ${ }^{* *}$ and Saleh Alatawi ${ }^{2}$}

${ }^{1}$ Civil Engineering Department, Faculty of Engineering, University of Tabuk, Saudi Arabia

${ }^{2}$ Vice Rector Office for Graduate Studies and Scientific Research, University of Tabuk, Kingdom of Saudi Arabia

\begin{abstract}
Constructing dams around the city of Tabuk is an important solution to controlling flood events, as well as increasing surface water budget and creating ground water recharge spots. The success of this effort is mainly based on locating the best site for a dam in the area. The aim of this study is to demonstrate the use of remote sensing, and geographic information system in dam site selection within the context of a catchment scale. Digital Elevation Model was used from the Advanced Spaceborne Thermal Emission and Reflection Radiometer (ASTER $30 \mathrm{~m})$ to characterise the catchment area. Enhanced Thematic Mapper Plus images $(E T M+)$ from LandSat 7 were used to classify the land cover in the study area. Several software packages such as ERDAS 11, Global Mapper 15.2 and ArcGIS 10.1 were used to construct and process the basic database. In addition, model builder from ArcGIS 10.1 was employed to construct a simplified model and integratesraster and vector datasets. The parameters of this model were: catchment slope (less 3\%), delineation network order more than or equal to 7 and Runoff Coefficient (0.4). Six suitable locations were chosen: Wadi Dam in connection with Wadi Al Baqqr, Wadi Na'am, Wadi Atanah, Wadi Abu Nishayfah A, Wadi Abu Nishayfah B and Qa'a Sharawra.
\end{abstract}

Keywords: Information technology; Azrid area; Flash flood; Remote sensing; DEM; Earth dams

\section{Introduction}

Flash flood affects both civilian and agricultural activities as the negative impact of flooding lasts a long time after the event. In addition to the unexpected flash flood, the morphological characteristics of an area may make the flash flood much worse, even catastrophic. To avoid this negative impact many projects are proposed by different authorities such as dams, tracking canals, or storm drainage systems. Ancient dams were certainly built to meet a single purpose, which is water harvesting and irrigation, e.g. Ma'rib dam of 1750 and $1700 \mathrm{BCE}$ [1]. Nowadays, there are multi-reasons for building modern dams and water structures (Figure 1):

i. Regulation of excess water and flood control

ii. Soil erosion and sediment control

iii. Drought control

iv. Irrigation

v. Generation of hydro-electric power

However, $60 \%$ of total stream flow is regulated by dams and reservoirs for flood control [2].

In general, there are different classifications of dams mainly based on engineering and study area aspects such as hydraulic design, structural design, usage of dams, construction material used and/or capacity. Based on construction material, earth dams account for $62 \%$ of all reported dams [2]. In addition, there are several considerations of dam construction:

i. Site topography and valley shape

ii. Geological structure and foundation conditions

iii. Availability of construction materials

iv. Overall cost
v. Spillway size and location
vi. Roadway
vii. Earthquake hazards
viii. Climatic conditions
ix. Environmental considerations
$\mathrm{x}$. Length and height of dam
xi. Life of dam

However, ground investigation is important before planning to construct an earth dam especially site selection and earthworks considerations. Generally, dams in arid regions, particularly, in Saudi Arabia, are built to guarantee water supply and reduce the negative impact of flood events. In fact, Tabuk city is suffering surface water scarcity compensated by flash flooding, which has been affecting the entire city for many years during the winter season. The catchment experienced major floods during the years 1981, 1988, 2010 and 2012. Excess water management is a key aspect of sustaining the water sector in the Kingdom of Saudi Arabia. Unexpected flash floods and strong population growth rates associated with high water needs for agriculture will increase pressure on water resources in Tabuk especially groundwater. In addition, flash flooding destroys the infrastructure of the city. However, water resources are limited and construction

*Corresponding author: Eyad Abushandi, Civil Engineering Department, Faculty of Engineering, University of Tabuk, Saudi Arabia, E-mail: eabushandi@gmail.com

Received November 15, 2014; Accepted January 22, 2015; Published January 24, 2015

Citation: Abushandi E, Alatawi S (2015) Dam Site Selection Using Remote Sensing Techniques and Geographical Information System to Control Flood Events in Tabuk City. Hydrol Current Res 6: 189. doi:10.4172/2157-7587.1000189

Copyright: () 2015 Abushandi E, et al. This is an open-access article distributed under the terms of the Creative Commons Attribution License, which permits unrestricted use, distribution, and reproduction in any medium, provided the original author and source are credited. 


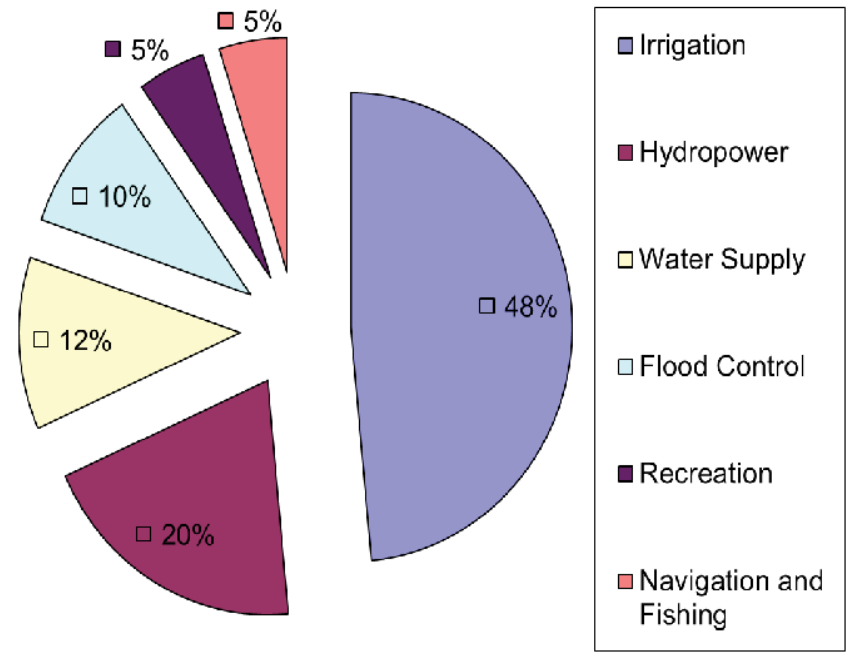

Figure 1: The distribution for multipurpose dams (after International Commission on Large Dams) (ICOLD, 2014).

of new dams will be an important part of the solution. At the initial stage of dam construction, full information on a selected site should be available for better planning and design. A tool for selecting the best site at Tabuk city catchment is the subject of this paper. After selecting suitable places for the dams, calculations of the inflow to the dam reservoirs is very important in order to forecast the amount of water received and design structures to control the inflow. In this case many hydrological and statistical models can be used such as IHACRES [3], ARMA, or ARIMA [4].

\section{GIS and remote sensing techniques in dam site selection}

Application of remote sensing and GIS techniques in hydrology is today one of the most effective approaches. Recently, remote sensing has provided valuable datasets to examine hydrological variables and morphological changes over large regions at different spatial and temporal scales (e.g. MSR-E, TRMM, GSMAP, ASTER, SAR and several others). Many researchers over the past 20 years have focused on satellite imagery applications in hydrology [5-9].

GIS and remote sensing can provide a huge amount of valuable data in spatial and temporal resolutions for areas where ground data are not easily available. In 2008, GIS and remote sensing techniques were applied by Forzieri et al. to assess the suitability of sites for the installation of small dams for the purpose of water harvesting in arid areas. The selection criteria are defined both in a qualitative and quantitative way. Qualitative criteria imply the identification of suitable valleys, wadi physical characteristics, based on satellite images interpretation - mainly DEM - and large-scale available cartography; other qualitative selection criteria concern the distance from settlements and infrastructures. Quantitative criteria were based on indexes that synthesise the effectiveness and feasibility of the possible interventions such as the alluvial plan index $(\alpha)$ and the hydrologic index $(P)$.

In a similar study, Singh et al. [10] used several remote sensing imageries to select dam sites. They used some parameters to select the sites including:

i) Slope (less than 10\%)

ii) Soil infiltration rate (moderate) iii) Land use (shrubs and river beds)

iv) Soil type (sandy clay loam)

The results proposed 14 dam sites which could be used for water harvesting and cultivation.

Information, such as terrain surface, wadis network, land use and catchment boundaries are important for dam site selection, which can be gathered from remotely sensed images. In particular, DEM can provide slope data which is the most influential factor on flood behaviour [11,12] described in detail a workflow for the Digital Elevation Model (DEM) preprocessing and extraction from ASTER images including accuracy estimation. In addition to the low spatial and temporal resolutions in the majority of remote sensing imagery, data accuracy in most related research is still a dilemma. A review by Sanyal and $\mathrm{Lu}$ [13] on the application of Remote Sensing in flood management noted that DEM model is the main part of flood hazard mapping. In particular, slopes data from DEM are useful for many hydrological studies and can be employed for dam location selection. Furthermore, a limited effort has been devoted in recent years to determine the capability of these techniques in assisting engineering dam design by allowing efficient, quick and economic data collection $[14,15]$. However, the application of remote sensing in ephemeral streams is limited compared with permanent rivers [16].

Kumar [17] used remote sensing and GIS techniques to assign the location of small water harvesting structures across streams/watersheds. Various thematic layers such as Landuse/Landcover, geomorphology and lineaments were used. These layers along with geology and drainage were integrated using GIS techniques to derive suitable water harvesting sites. In addition to the suitable site selection of the dams, they calculated the storage and transmittance of groundwater in the study area. Youssef et al. [18] furthermore, proposed three dam site locations for Jeddah City in Saudi Arabia based on topographical analysis using different data sets such as topographic maps, remote sensing images, a digital elevation model with $90-\mathrm{m}$ resolution (STRM 2000) and geological map. In addition, these selected locations were in the outlet areas where large tracts of land could be temporarily inundated by water as a result of water being held back by the proposed dam.

Martire et al. applied most recently satellite data (Synthetic Aperture Radar (SAR)) for the precise monitoring of earth dams ground deformation. They found high agreement between final SAR and in-situ instrumental data, which demonstrated the reliability of such a technique for future use.

Besides ground application, remote sensing can be used in the case of atmospheric variables such as cloud thickness, relative humidity and Evapotranspiration (ET) vital for water resource management such as MODIS application in ET [19] and GSMaP [7].

\section{Catchment characteristics}

The study area is located in the north-western part of Saudi Arabia (Figure 2) about $96 \mathrm{Km}$ southwest of the Jordanian border. The study area covers about $20892.6 \mathrm{~km}^{2}$. In terms of aridity, the catchment is classified as hyper-arid, which means high evaporation rate, low vegetative cover and flash flood due to unexpected rainfall storms. There are two main climatic seasons in Tabuk: winter season with limited rainfall storms and a hot and dry summer. The annual rainfall in Tabuk is around $33 \mathrm{~mm}$; the main rainfall occurs in the wet season between October and April. 


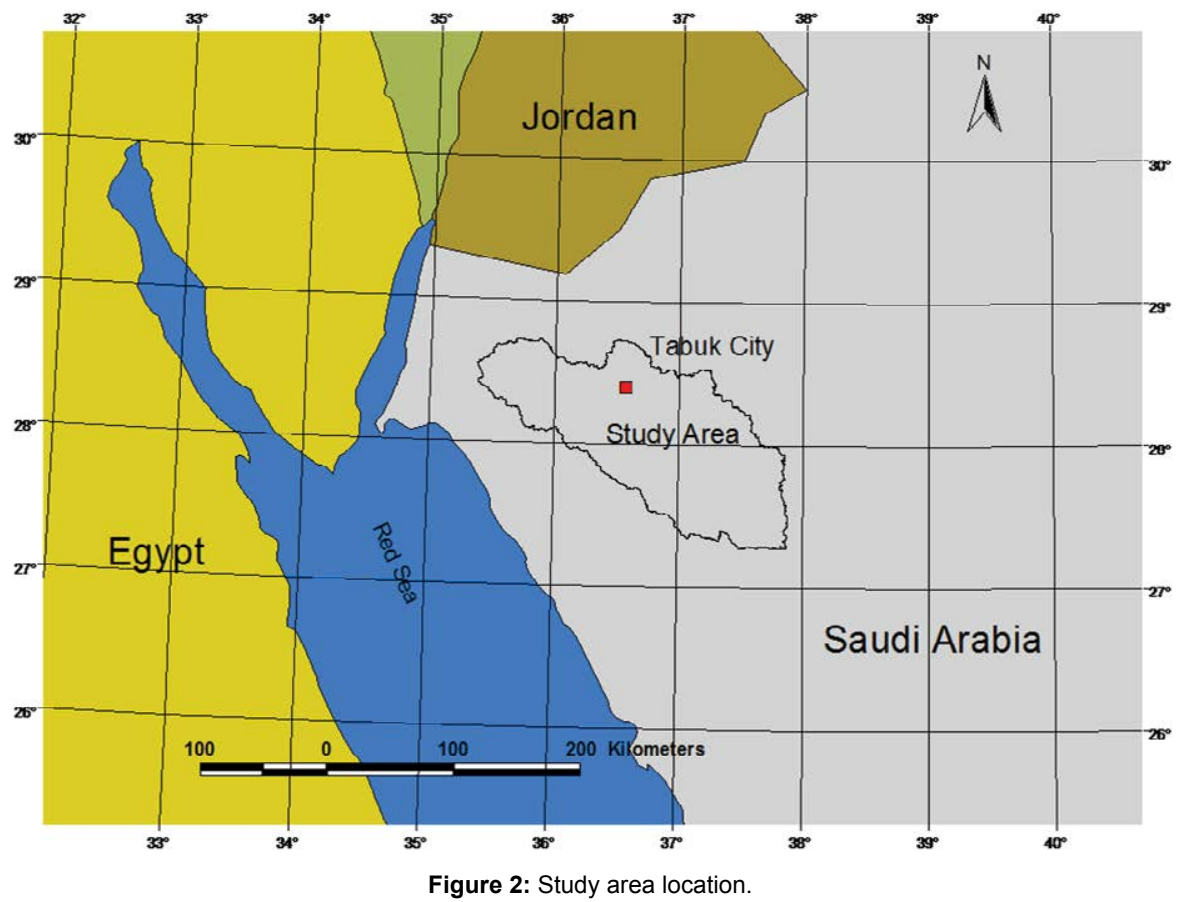

\section{Materials and Method}

Digital elevation data from ASTER, $30 \mathrm{~m}$ resolution, were used to derive the geomorphological structure. The boundaries and wadis network for Tabuk catchment were derived from the digital elevation data using River Tools V. 2.4. Further processes including modelling, stratification of different layers and orders were conducted using ArcGIS V. 10.0. The path profiles and wadis tracking were conducted using Global Mapper V.15.2. There are five main wadis crossing Tabuk City from east to west (Figure 3):
i. Wadi Al-Akhdar
ii. Wadi Abu Nishayfah
iii. Wadi Na'am
iv. Wadi Al Baqqar (extension from Wadi Ayrin and Wadi Al Hadarah)
v. Wadi Damm

The names of the wadis are common but might be changed from one area to another and all ended at a single outlet called Qa'a Sharawra. The area of Qa'a Sharawra is around $253 \mathrm{Km}^{2}$. The wadis are mainly generated from three main mountain series surrounding the city of Tabuk from the east and west parts: Ghawanim Mountains, Rays Mountains and Asafir Mountains (Figure 4). However, these mountain series create slope zones which have potential for flood and soil erosion.

Wadi Al-Akhdar is generated from Ghawanim Mountains in the east and is $68 \mathrm{~km}$ long (Figure 5). The wadi is connected to Wadi Mishash Bani Atiyah and Tuus Al Arqanah in the upland. However, the wadi does not directly cross the city of Tabuk.

Wadi Abu Nishayfah is the longest wadi $(226 \mathrm{~km})$ in the catchment and crosses directly the city of Tabuk. Therefore, the flood behaviour in this wadi is important for any flood protection projects. The wadi is generated from Nahamah Mountain in the southern part of the catchment. The wadi has many feeding spots and sub-streams along the way from both sides east and west (Figure 6). Geomorphologicaly, at the distance of $207 \mathrm{~km}$ from its generation point and before crossing the city of Tabuk, Wadi Abu Nishayfah is connected to Wadi Ar Radwan.

Wadi Na'am is around $60 \mathrm{~km}$ long and generated from a series of mountains from the western part of the catchment, namely: Jibal Al Asafir (1257 m above sea level) and Jibal As Salitiyat (1190 above sea level) (Figure 7). The wadi also has many feeding spots and sub-streams along the way from the west and south parts especially in the first $15 \mathrm{~km}$ from the generation site. In addition, there are some sharing streams between Wadi Na'am and Wadi Atanah.

Wadi Al Baqqar is the extension of Wadi Al Hadarah and slightly connected to Wadi Ayrin. They are all generated from Jibal Al Asafir and Jibal As Salitiyat (Figure 8).

Wadi Damm crosses many mountain series from the northwestern part of the catchment, but relatively lower elevations such as Al Baydi Mountain (elevation $961 \mathrm{~m}$ ), Umm Jiba Mountains (elevation 1008m), Shuka'ah Mountains (elevation $978 \mathrm{~m}$ ) and many others. This means the wadi has many feeding sub-streams. Wadi Damm is around 137 $\mathrm{km}$ long (Figure 9).

The figures from 5 to 9 show the longitudinal profiles of the wadis which have a gradually lower gradient as they movie from west or south to the north. The figures show marked variations in wadis -floor slope over relatively short distances. However, the longitudinal profiles show the linear features in order to define the channel sections to the direction of flow. This concept will provide useful information concerning flood plains and possible over spilling. These information are important to model parameters of selected control sites.

\section{Statistical rational method}

The Statistical Rational Method was used to compute runoff coefficient. The Rational Method equation is: 
Citation: Abushandi E, Alatawi S (2015) Dam Site Selection Using Remote Sensing Techniques and Geographical Information System to Control Flood Events in Tabuk City. Hydrol Current Res 6: 189. doi:10.4172/2157-7587.1000189

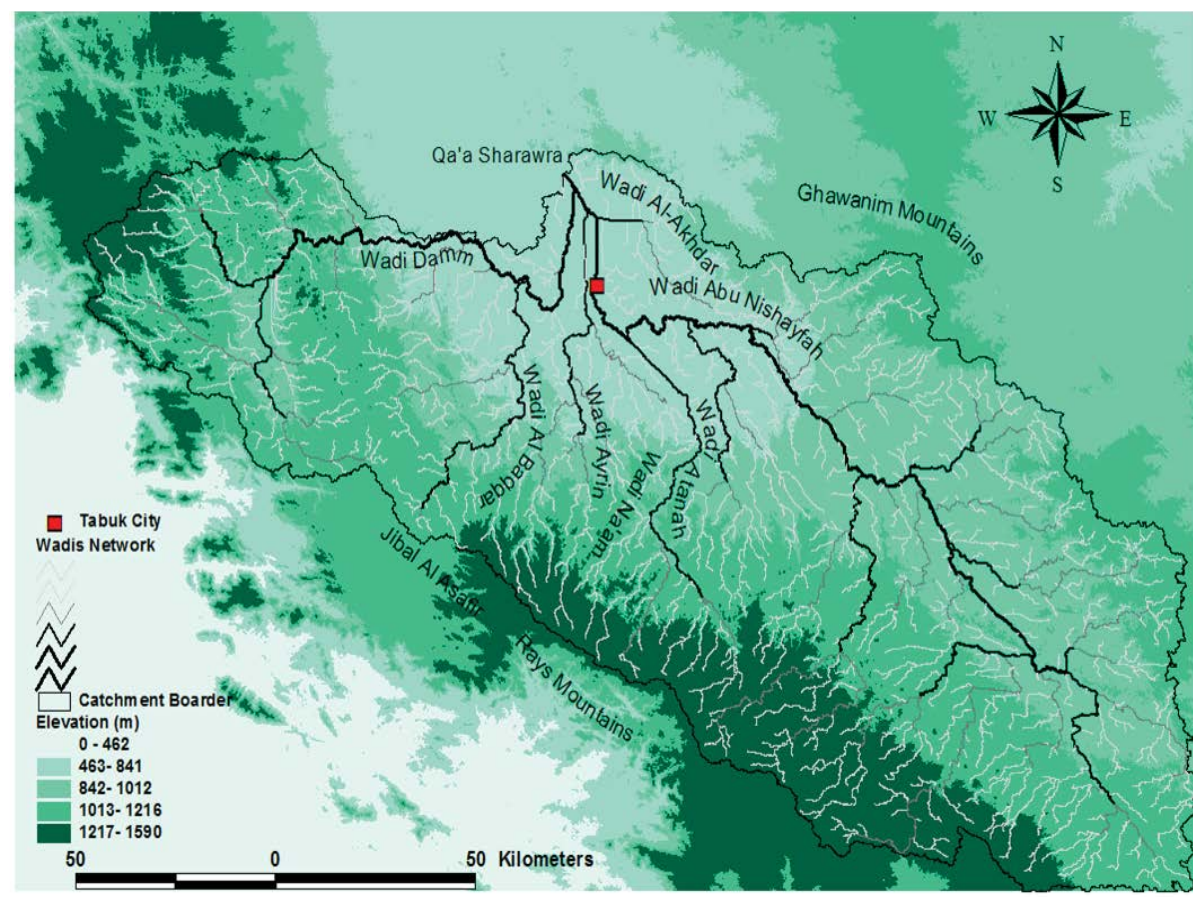

Figure 3: Altitude and catchment network of Tabuk.
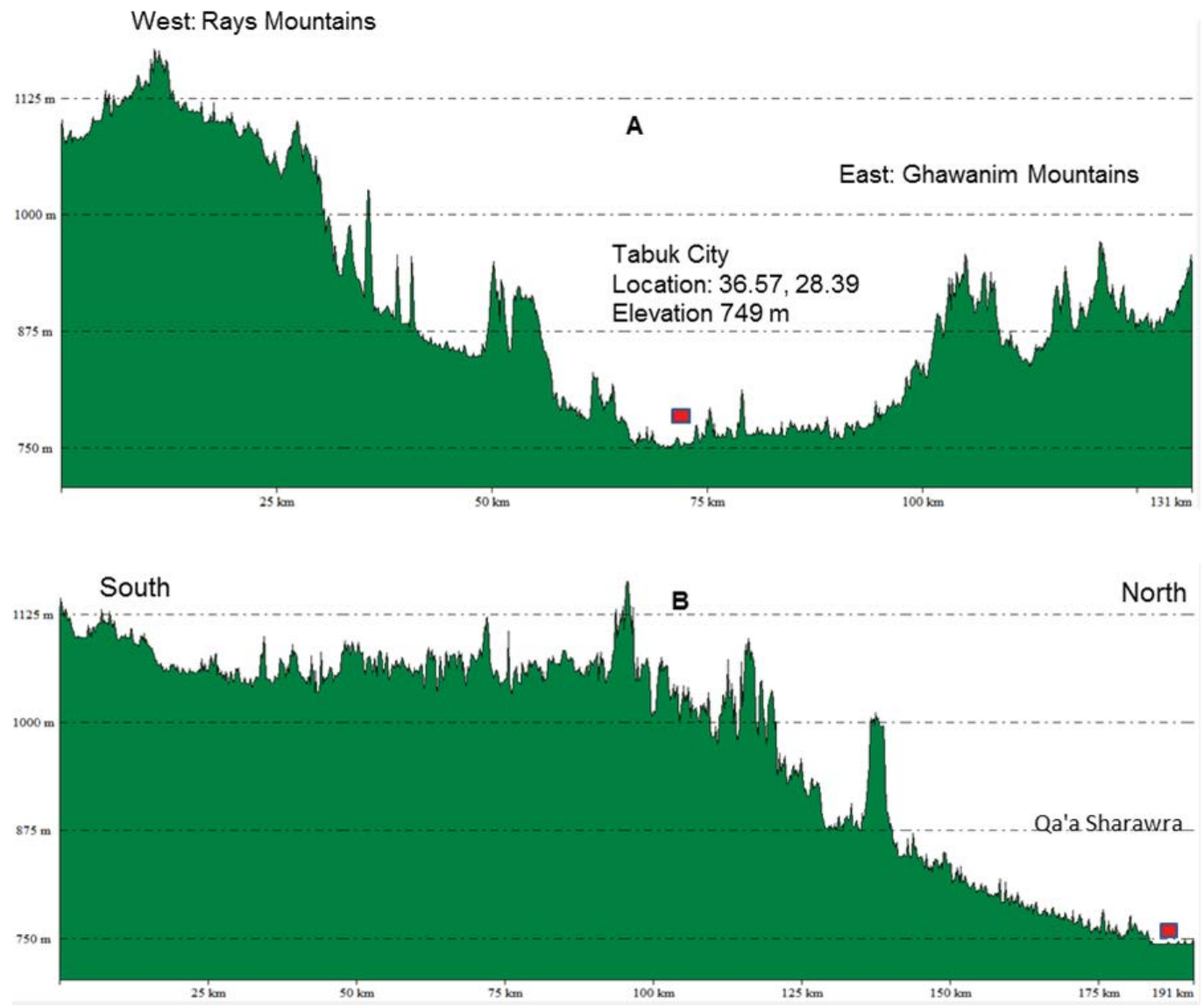

Figure 4: A: Cross section of Tabuk Catchment from West to East, B: longitudinal section from South to North. 


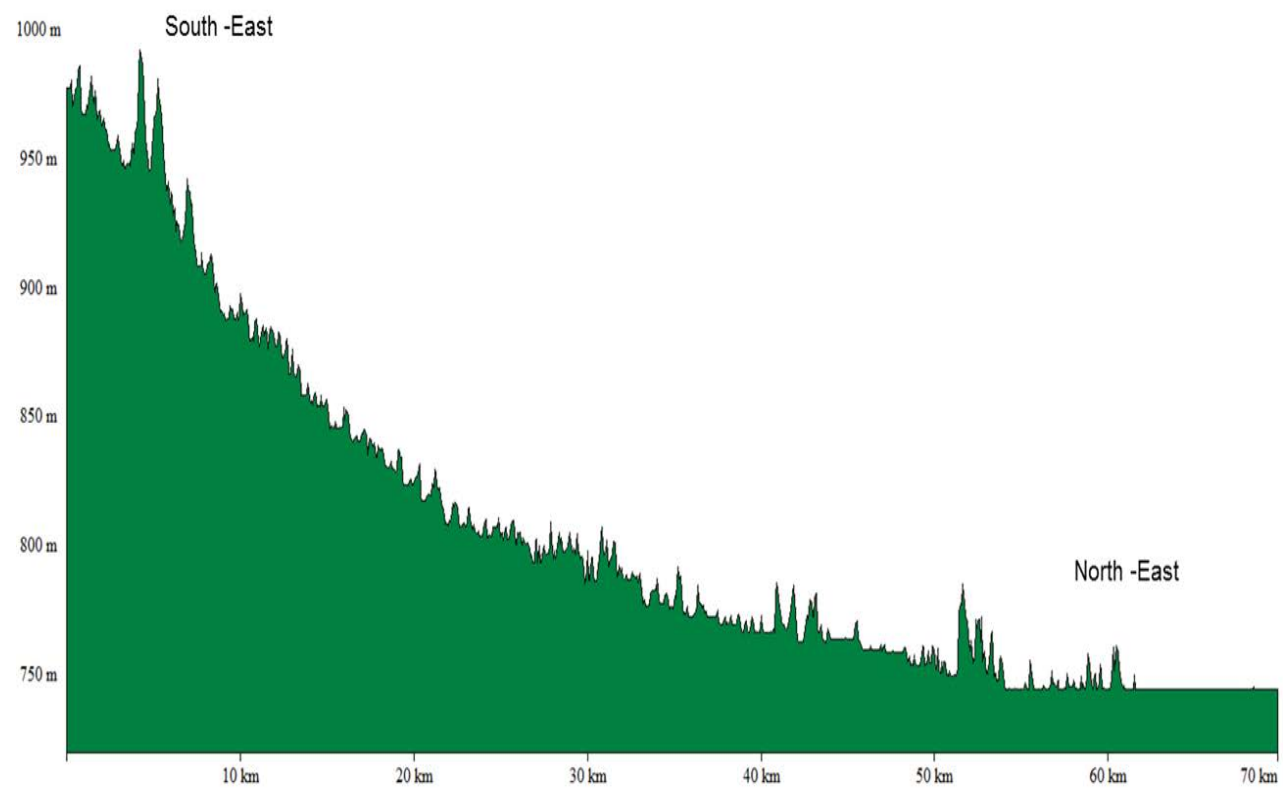

Figure 5: Longitudinal section of Wadi Al-Akhdar.

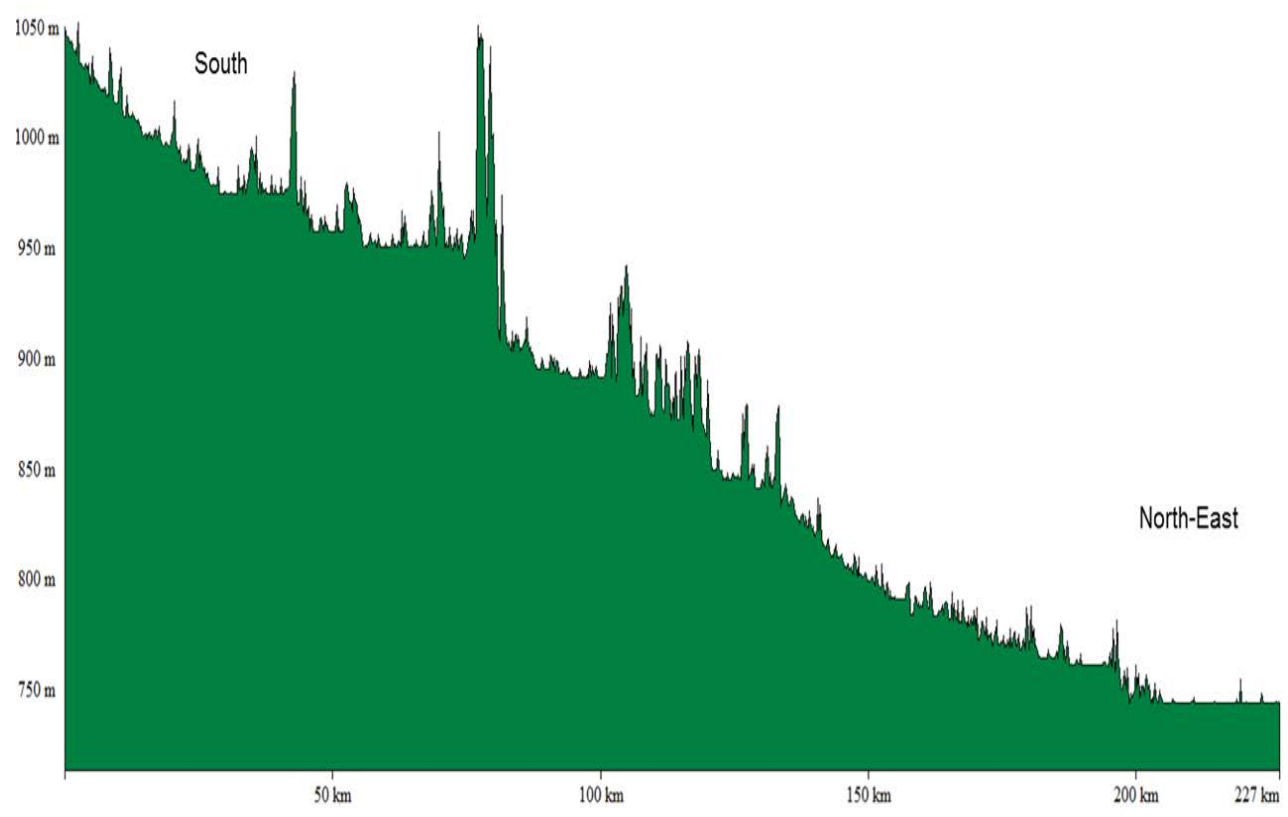

Figure 6: Longitudinal section of Wadi Abu Nishayfah.

\section{$\mathrm{Q}=\mathrm{CIA} \quad$ Equation 1}

Where $\mathrm{Q}=$ Runoff in cubic feet per second (cfs), C=Runoff coefficient, I=Rainfall intensity (inches per hour) and $\mathrm{A}=$ Drainage area (acres). The main parameters that determine Runoff Coefficient (C) are: i) Land cover type, ii) Slope, iii) Soil type. Spatial analysis of the land cover types was successfully applied using ETM+ to classify land cover types for Tabuk Catchment. Because of available ground knowledge about land cover identity and distribution, supervised classification was successfully applied to estimate these types with high accuracy referring to ground truth data. In addition, the extracted information on land use types and their spatial distribution was used to select Runoff Coefficient (C). Finally, ArcGIS Model builder model was used to run the best location of the dams based on the following parameters (Figure 10):

i. Catchment Slope (less than 3\%).

ii. Delineation network order more than or equal to 7

iii. Runoff Coefficient (0.4) 


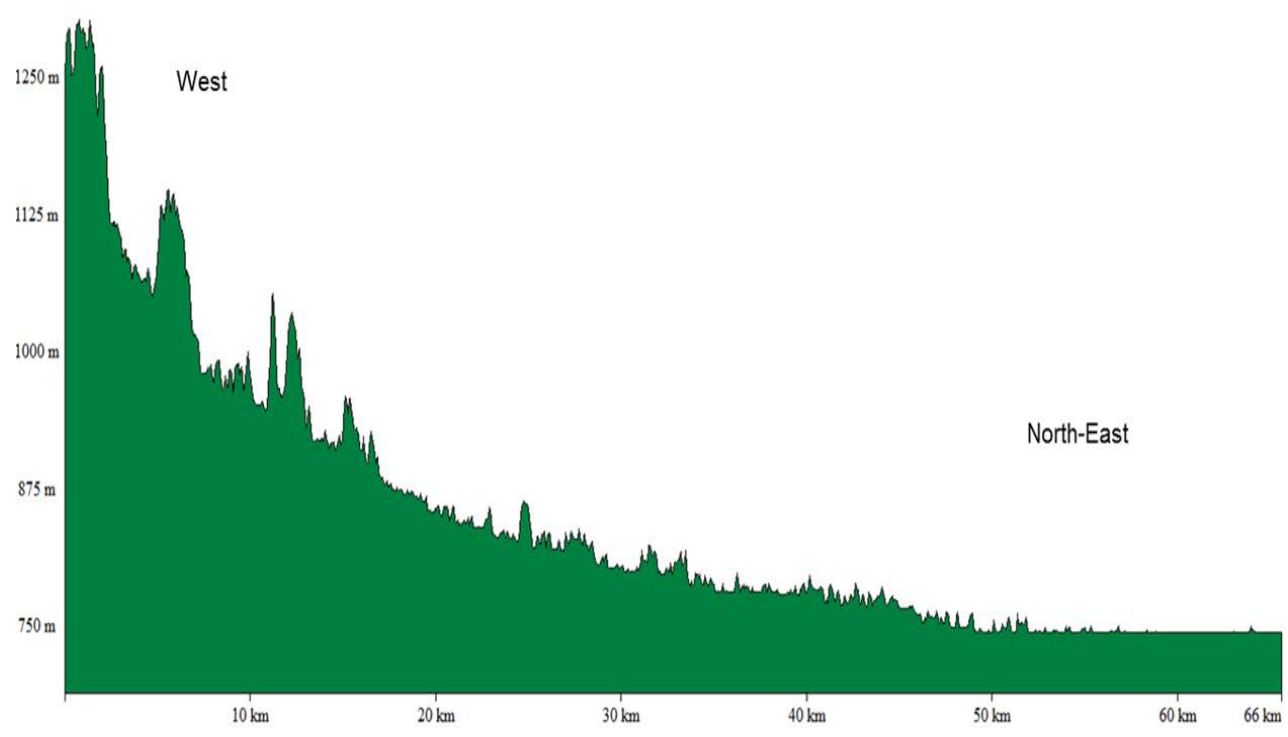

Figure 7: Longitudinal section of Wadi Na'am.

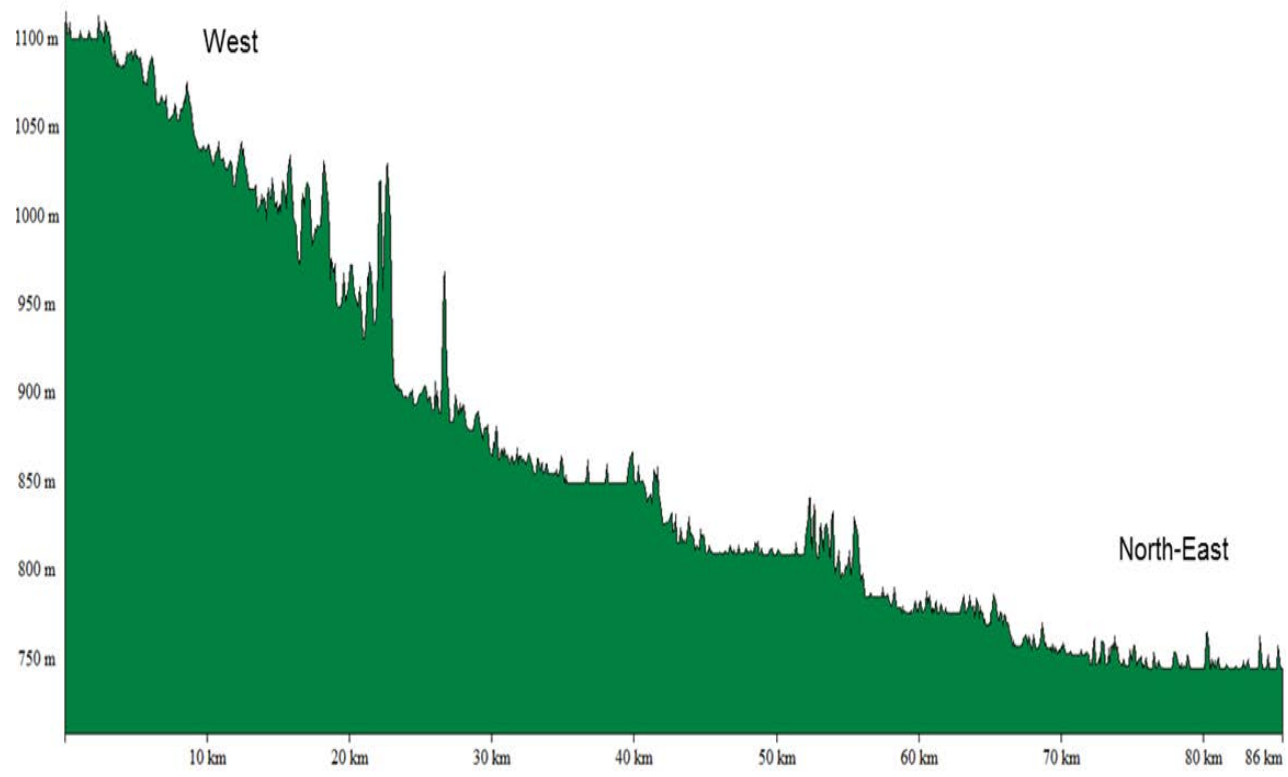

Figure 8: Longitudinal section of Wadi Al Baqqr.

\section{Results}

Land cover types are determined for Tabuk Catchment by applying supervised classification on Landsat TM images. The ETM+ data were processed using ERDAS software and further analysis of the land cover map was conducted with ArcGIS 10.0. A set of seven land use/land cover classes were chosen for Tabuk catchment. The land cover types map and distribution (Figures 11 and 12) show that the major land cover types include: i) Weathered Eroded Rocky Land, ii) Eroded Flooded Land, iii) Low Land. Because Tabuk area is a hyper-arid regime, land cover is characterised by fragmented landscapes with low availability of vegetation cover.
According to the land cover map and Rational Method empirical table [20], Runoff Coefficient (C) was calculated (Table 1).

Different geospatial data sets and analyses have been extracted and conducted from ASTER image including network delineation, slope map, side flow, sub-basin and wadis longitudinal and cross sections. Based on the sub-basins areas from ASTER analysis around 95\% of water contributing flood events in Tabuk City runs from outside (Figure 13). In addition, the sub-basins within area greater than 130 $\mathrm{km}^{2}$ are mainly in the higher altitudes located 50-220 km from the city.

Basically, ASTER and ETM+ data sets are the main inputs into the ArcGIS Model builder. To find suitable dam location, the constructed 


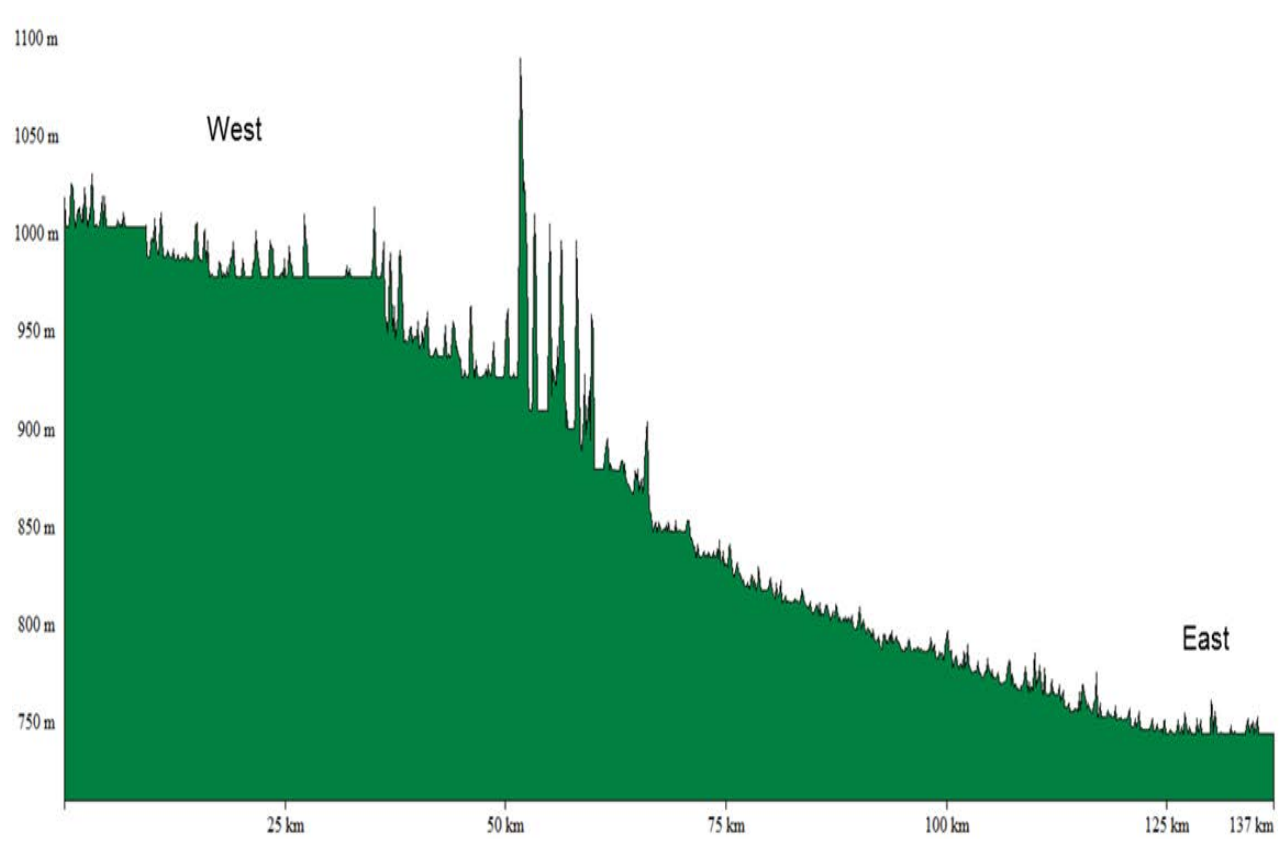

Figure 9: Longitudinal section of Wadi Damm

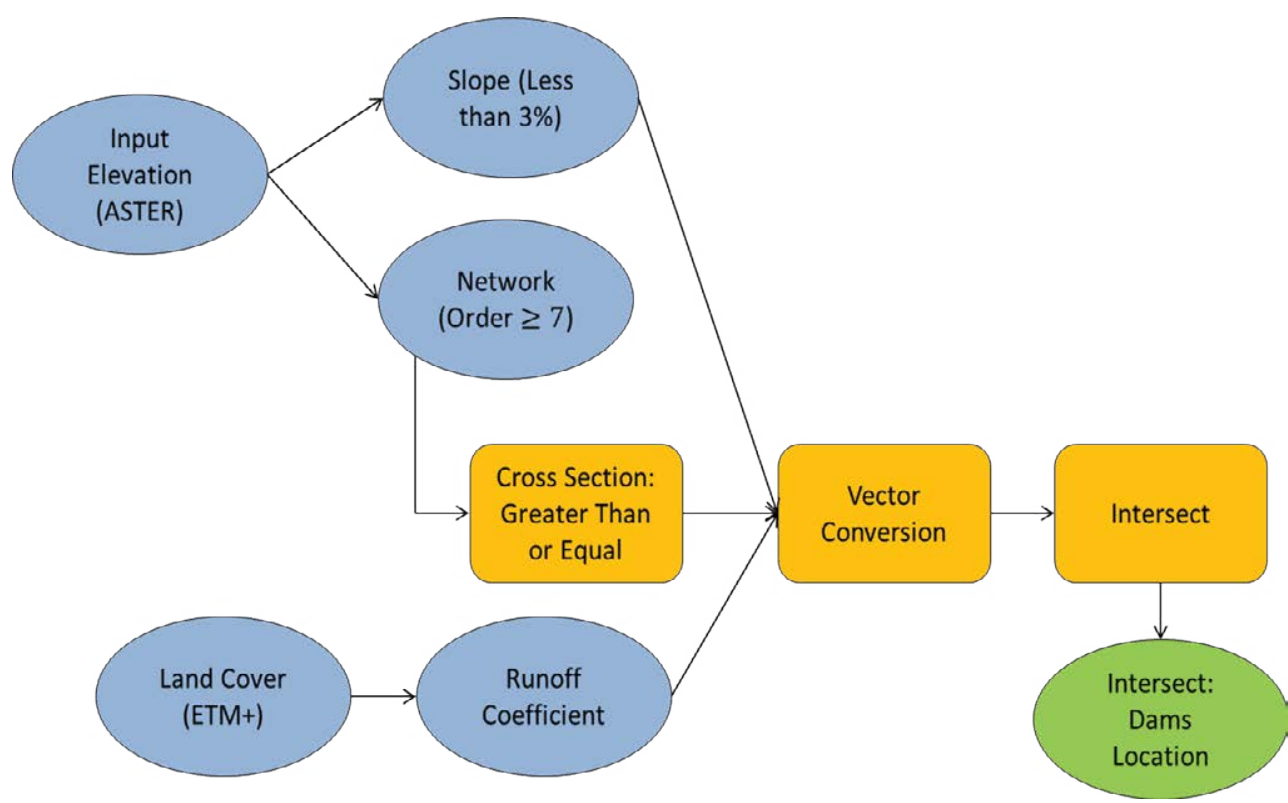

Figure 10: Dam Location Simplified Model Flowchart.

model in the ArcGIS Model builder used different parameters: slope less than $3 \%$, delineation network order more than or equal to 7 with cross section (Net Diameter) greater than or equal to $500 \mathrm{~m}$, continuity of at least $20 \mathrm{~km}$ and $40 \mathrm{~km}$ distance between two dams proposal on each wadi. As a cross factor the model used Low Land class because it has the lowest Runoff Coefficient which is equal to 0.4 and connects the major wadis. According to the geomorphological analyses, six sites were selected to build dams (Figure 14). The locations of the dams are as follows:

i. Wadi Damm in connection with Wadi Al Baqqr
ii. Wadi Na'am
iii. Wadi Atanah
iv. Wadi Abu Nishayfah A
v. Wadi Abu Nishayfah B
vi. Qa'a Sharawra

\section{Discussion}

Digital elevation models (DEMs) as well as layers produced by 
Citation: Abushandi E, Alatawi S (2015) Dam Site Selection Using Remote Sensing Techniques and Geographical Information System to Control Flood Events in Tabuk City. Hydrol Current Res 6: 189. doi:10.4172/2157-7587.1000189

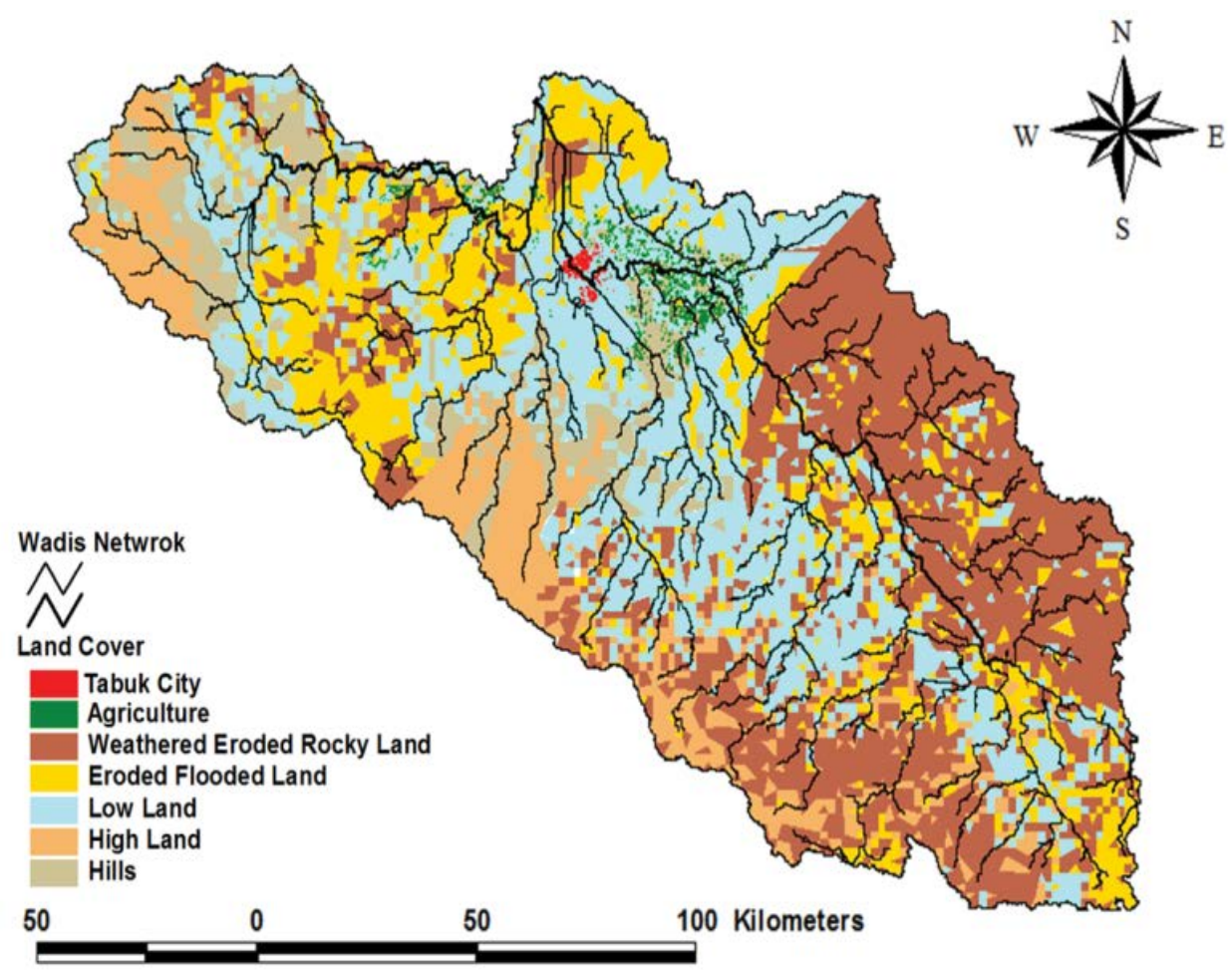

Figure 11: Land cover classification based on Landsat TM images acquired in May 2006.

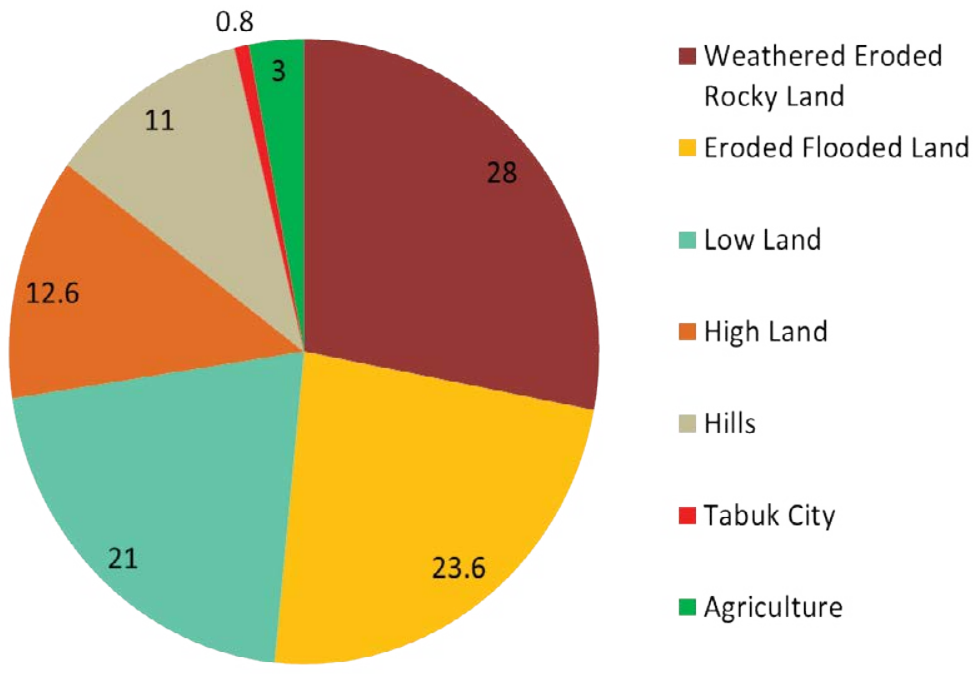

Figure 12: Land cover types percentages.

\begin{tabular}{|c|c|c|}
\hline Class Name & C Value & A $\left(\mathrm{Km}^{2}\right)$ \\
\hline Weathered Eroded Rocky Land & 0.7 & 5849.928 \\
\hline Eroded Flooded Land & 0.6 & 4930.6536 \\
\hline Low Land & 0.4 & 4387.446 \\
\hline Hills & 0.7 & 2298.186 \\
\hline High Land & 0.7 & 2632.4676 \\
\hline Tabuk City & 0.9 & 167.1408 \\
\hline Agriculture & 0.5 & 626.778 \\
\hline
\end{tabular}

Table 1: Runoff Coefficient (C) values. 


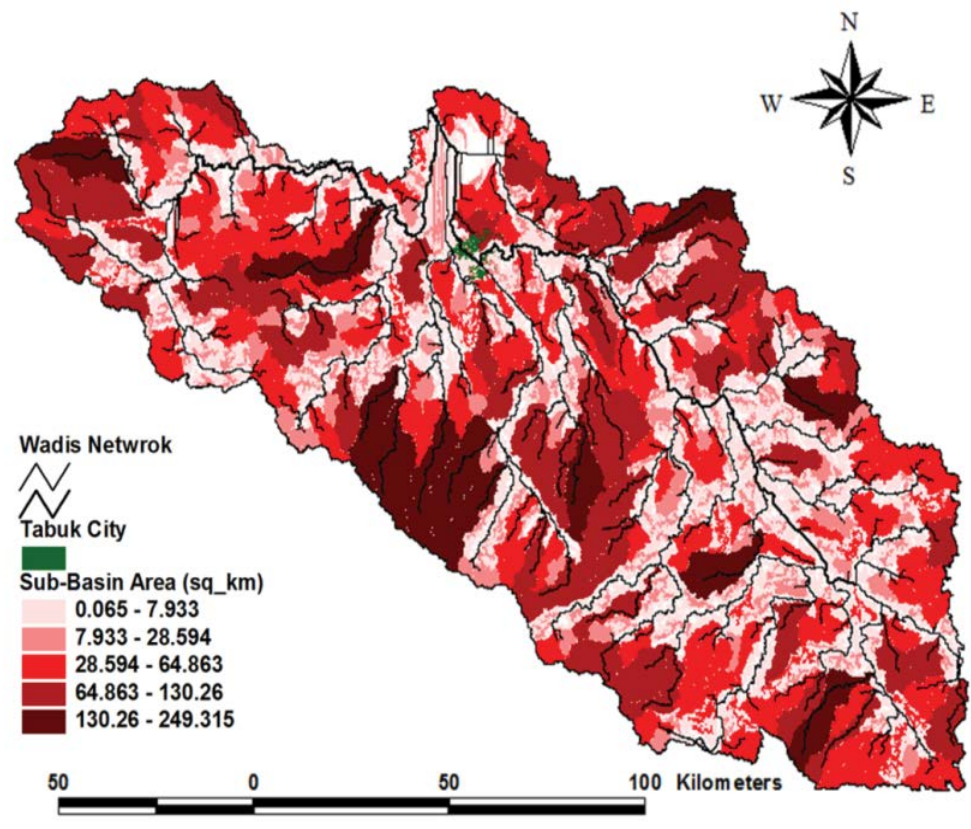

Figure 13: Sub-Basin Analysis of Tabuk Catchment.

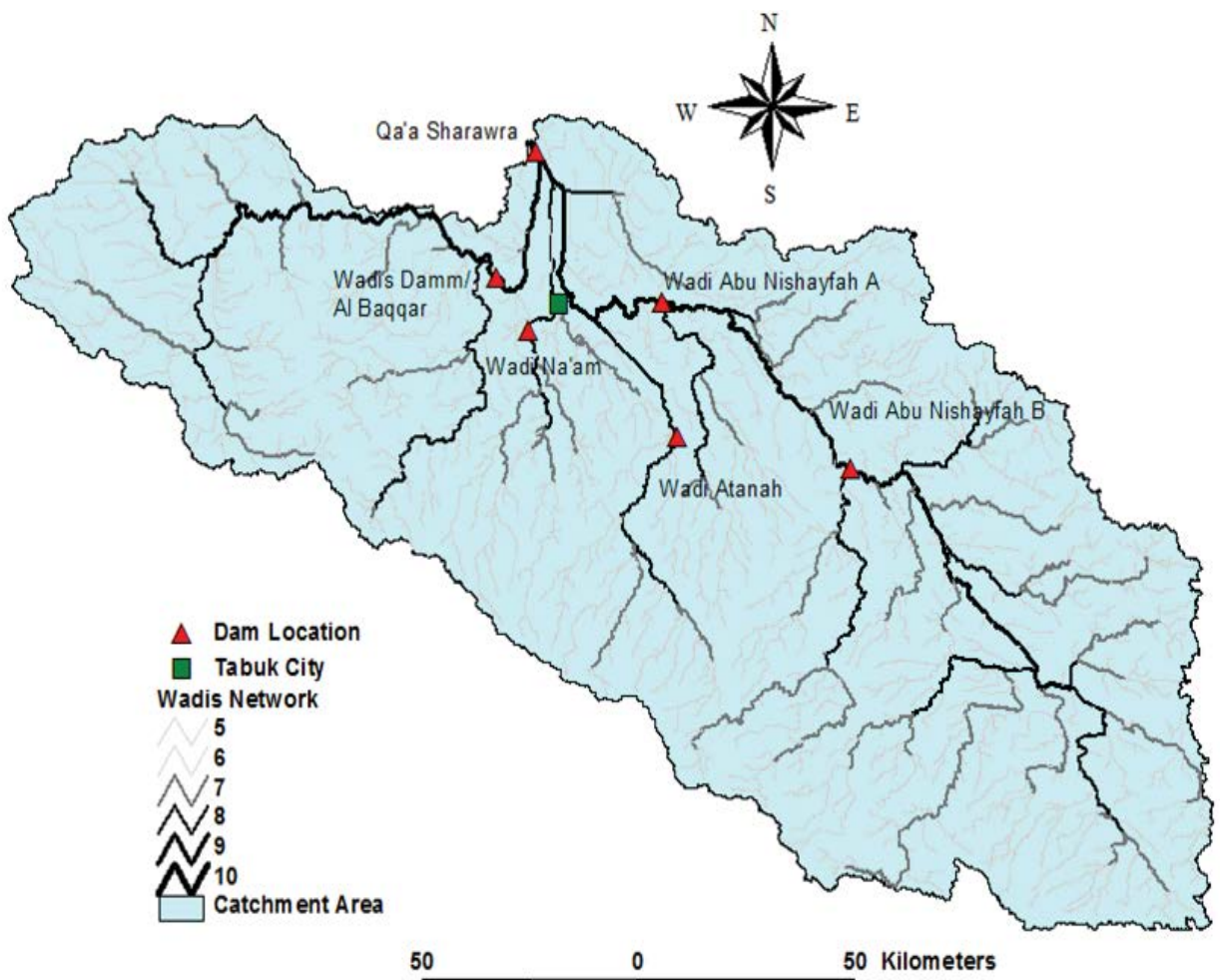

Figure 14: The location of the six dam sites based on a simplified model.

RS and GIS provide a solid geospatial data foundation, which is suitable for addressing questions on choosing the best sites of dams. To accomplish this, there is a need to understand geospatial processes of gathering, organising and analysing data using RS and GIS. On the other hand, theoretical and practical backgrounds are needed to understand linkages, relationships and thresholds that allow faster identification of the study area. DEMs are essential for topographic characterisation by representing land surface, hydrological boundaries 
Citation: Abushandi E, Alatawi S (2015) Dam Site Selection Using Remote Sensing Techniques and Geographical Information System to Control Flood Events in Tabuk City. Hydrol Current Res 6: 189. doi:10.4172/2157-7587.1000189

Page 10 of 13

and terrain attributes, such as slope and aspect. In addition, DEMs are useful to model the distribution of flood site potential and topographic moisture with a resolution not more than $30 \mathrm{~m}$ (cell size). Concerning the accuracy of DEMs research has indicated that $10-20$ $\mathrm{m}$ resolution is required to depict accurately topographic features and other biophysical processes [21]. The scope of this paper is achieved by developing a method needed to address the complex morphological relationships for selecting suitable dam location in an arid catchment (Tabuk/Northwest). Software such as ArcGIS (ESRI) provides modelling tools to achieve spatial data visualisation in geographic space and time. The intersection function in ArcGIS is used to compute the common parameters in the study area including catchment slope, delineation network and Runoff Coefficient, taking into account the continuity of the stream and the distance between two dams proposal on each wadi. The values of these parameters were logically chosen, e.g. slope less than $3 \%$ indicates the flattest area, wadi network order greater than 7 has all sub stream and feeding points clustered, Runoff Coefficient is less or equal to 4 meaning the water collection will be in the Low Land class. In addition, the length and the stream width play an important role in dam selection. The missing important parameter is the spatial distribution of soil type to achieve higher credibility of the selected sites.

In terms of dam type, embankment (earth) dams can be used

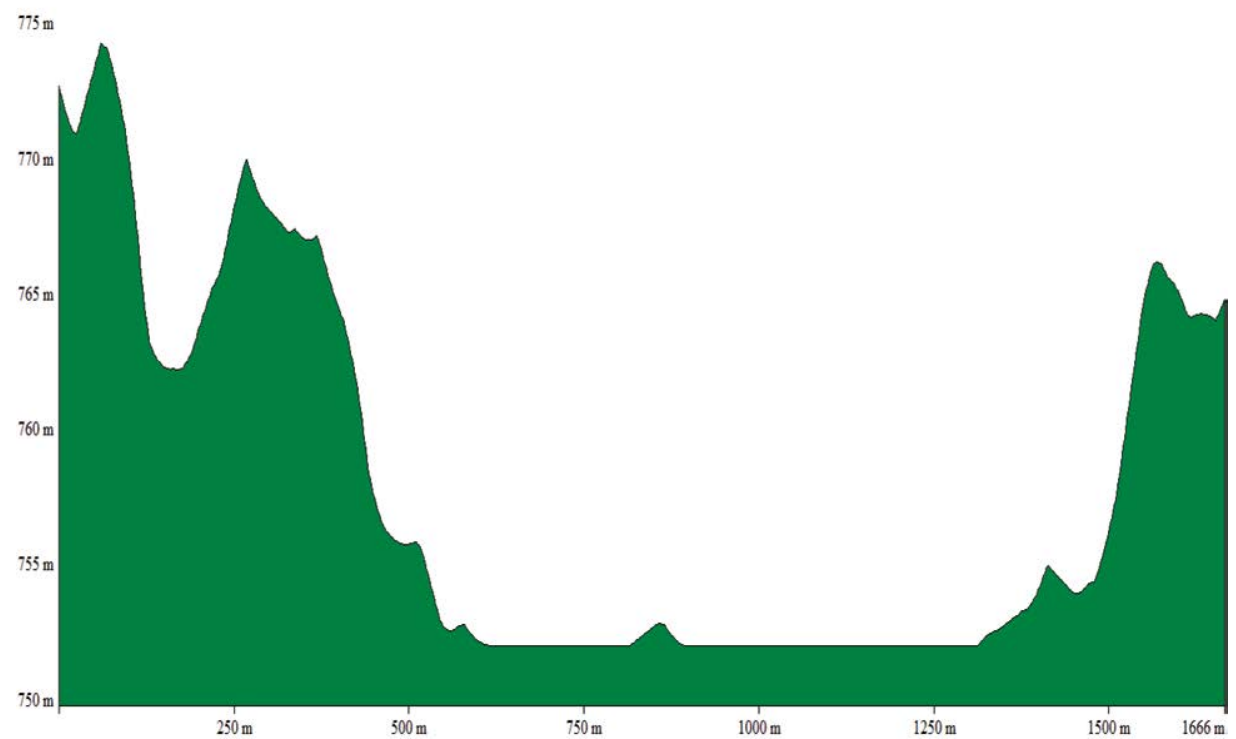

Figure 15: Cross Section of the first Dam Location: Wadi Damm in connection with Wadi Al Baqqr Coordinate (36.38E, 28.44N), Elevation $752 \mathrm{~m}$ above sea level, order No. 9.

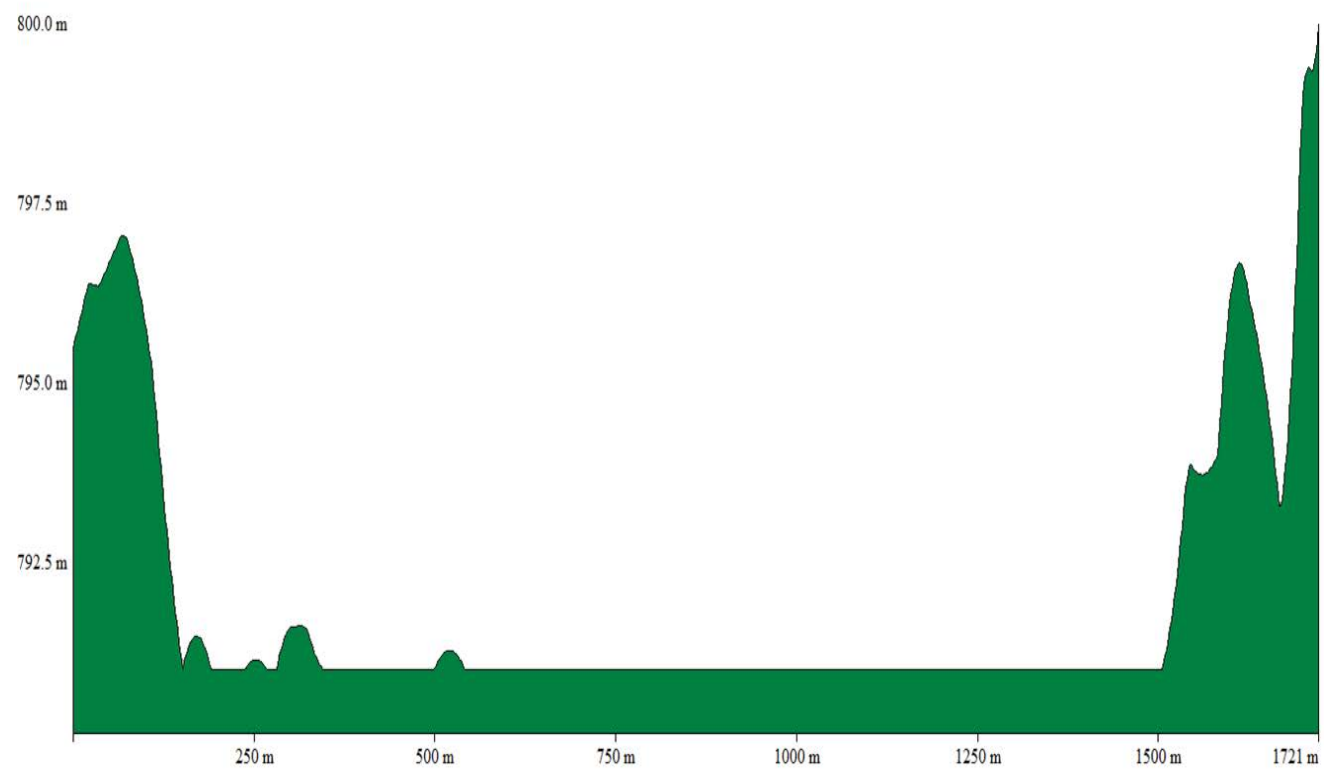

Figure 16: Cross Section of the first Dam Location: Wadi Abu Nishayfah A, Coordinate (36.86E, 28.28N), Elevation $790 \mathrm{~m}$ above sea level, order No. 9. 
Citation: Abushandi E, Alatawi S (2015) Dam Site Selection Using Remote Sensing Techniques and Geographical Information System to Control Flood Events in Tabuk City. Hydrol Current Res 6: 189. doi:10.4172/2157-7587.1000189

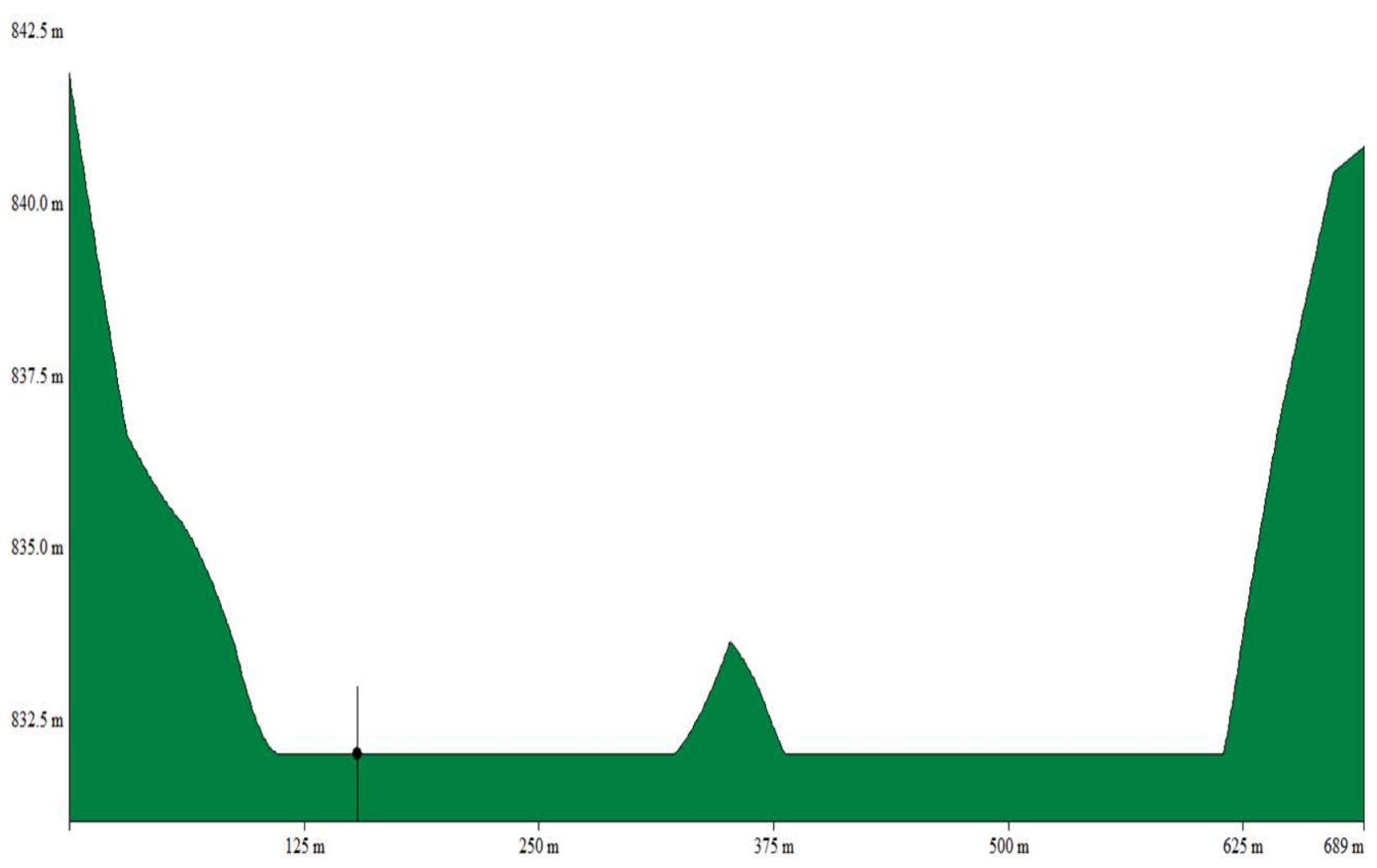

Figure 17: Cross Section of the first Dam Location: Wadi Atanah, Coordinate (36.75E, 28.17N), Elevation $832 \mathrm{~m}$ above sea level, order No. 8.

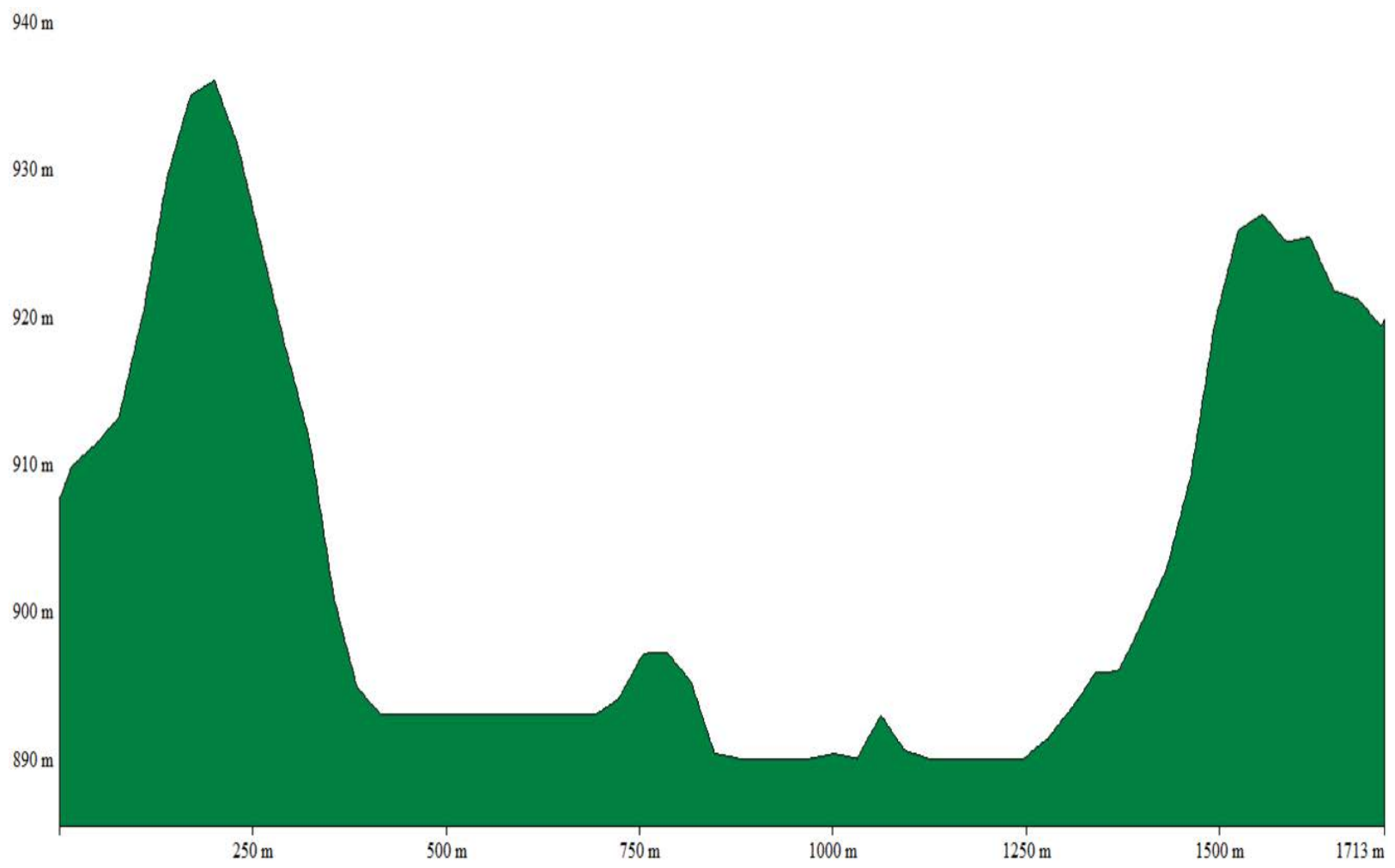

Figure 18: Cross Section of the first Dam Location: Wadi Abu Nishayfah B, Coordinate (37.22E, 28.08N), Elevation $790 \mathrm{~m}$ above sea level, order No. 9. 


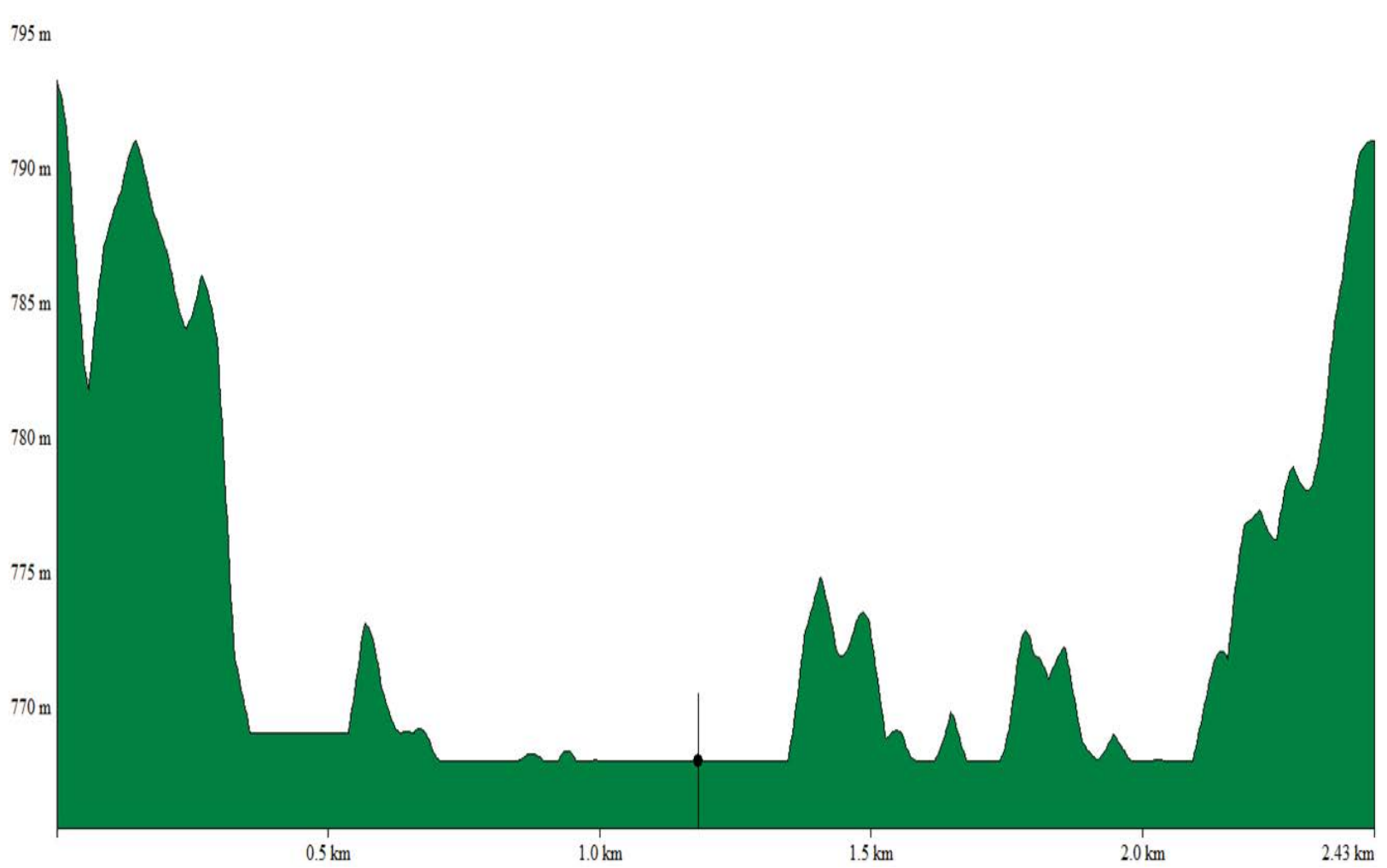

Figure 19: Cross Section of the first Dam Location: Wadi Na'am, Coordinate (36.44E, 28.33N), Elevation $768.5 \mathrm{~m}$ above sea level, order No. 8.

to protect the city of Tabuk from flash flood event, at the same time harvesting water and creating ground water recharge spots. Furthermore, the six sites which were selected to build dams require a range of cut and fill earthworks operations from low to high range of operations, e.g. the locations of Wadi Damm in connection with Wadi Al Baqqr (Figure 15) and Wadi Abu Nishayfah A (Figure 16), and Wadi Atanah (Figure 17) require low range operations, while the locations of Wadi Abu Nishayfah B (Figure 18) and Qa'a Sharawra need moderate operation. Finally, the location of Wadi Na'am requires full cut and fill operations (Figure 19). The cross section of the wadis are very important in many aspects:

i. Construction cost calculations

ii. Dams storage calculation

iii. Stability and risk assessment

There are many methods based on information technology used in suitable dam location such as image differencing, vegetation index differencing, selective principal components analysis, direct multi-date classification, post-classification analysis, etc.

Finally, it is useful to recognize that anthropogenic changes can be the most typical and serious factors of land cover change, through direct and indirect effects.

\section{Conclusion}

Spatial analysis was applied using Landsat Thematic Mapper images (Landsat TM) to detect land cover type in a certain period. Land cover types have been classified successfully using supervised classification referring to ground truth data. DEM information (slope, network delineation, boundaries) was extracted from ASTER images. Analysis of these datasets using different software packages accurately reflects the development of the technology and software in order to construct a net between modelling approach and software. Finally, all information extracted from satellite imageries is imported into ArcGIS (Model Builder), and spatial analysis is carried out to identify the best dam location. According to the intersection of different parameters and analyses, six sites were selected to build earth dams. All sites require earthworks operations in the range from low to high range, which accordingly affect the cost of the operation. The achieved results demonstrate the great potential of ETM+ and ASTER satellite imagery for hydrology applications at acceptable scales.

\section{Acknowledgement}

The authors would like to acknowledge financial support for this work from the Deanship of Scientific Research (DSR), University of Tabuk, Tabuk Saudi Arabia under grant no. 2/052/1435, and ongoing project entitled "Topographic Study of Tabuk Wadis: Changes and Behavior During Flash Flood Events".

\section{References}

1. Hill R (1996) Irrigation and water supply, A History of Engineering in Classical and Medieval Times. Routledge 17-46.

2. International Commission on Large Dams (ICOLD) (2014) Dams genera synthesis.

3. Jakeman J, Littlewood G, Whitehead G (1990) Computation of the instantaneous unit hydrograph and identifiable component flows with application to two small upland catchments. Journal of Hydrology 117: 275-300.

4. Valipour M, Banihabib M, Behbahani S (2013) Comparison of the ARMA, ARIMA, and the autoregressive artificial neural network models in forecasting the monthly inflow of Dez dam reservoir. Journal of Hydrology 476: 433-441.

5. Kite W, Pietroniro A (1996) Remote sensing applications in hydrological modelling. Hydrol Sci 41: 563-591. 
Citation: Abushandi E, Alatawi S (2015) Dam Site Selection Using Remote Sensing Techniques and Geographical Information System to Control Flood Events in Tabuk City. Hydrol Current Res 6: 189. doi:10.4172/2157-7587.1000189

6. Liu J, Chen JM, Cihlar J (2003) Mapping evapotranspiration based on remote sensing: An application to Canada's landmass. Water Resour Res 39: 1189.

7. Forzieri G, Gardenti M, Caparrini F, Castelli F (2008) A methodology for the pre-selection of suitable sites for surface and underground small dams in arid areas: A case study in the region of Kidal. Physics and Chemistry of the Earth 33: 74-85.

8. Abushandi E, Merkel B (2011) Rainfall estimation over the Wadi Dhuliel arid catchment, Jordan from GSMaP_MVK+. Hydrol. and Earth Syst Sci 8: 16651704.

9. Mahmoud S (2014) Investigation of rainfall-runoff modeling for Egypt by using remote sensing and GIS integration. CATENA 120: 111-121.

10. Singh P, Singh D, Litoria P (2009) Selection of suitable sites for wate harvesting structures in Soankhad watershed, Punjab using remote sensing and geographical information system (RS\&GIS) approach-A case study. Journal of the Indian Society of Remote Sensing 37: 21-35.

11. McCabe M, Kustas W, Kongoli C, Ershadi A, Hain C (2013) Global-scale estimation of land surface heat fluxes from space: current status, opportunities, and future directions, in: Petropoulos. Remote Sensing of Energy Fluxes and Soil Moisture Content, E-Publishing Inc., Pp 447-462.

12. Shafapour M, Pradhan B, Mansor S, Ahmad N (2015) Flood susceptibility assessment using GIS-based support vector machine model with different kernel types. Catena 125: 91-101.

13. Sanyal J, Lu X (2004) Application of remote sensing in flood management with special reference to monsoon Asia: A Review. Nat. Hazard 33: 283-301.
14. Salih SA, Al-Tarif ASM (2012) Using of GIS spatial analyses to study the selected location for dam reservoir on Wadi Al-Jirnaf, West of Shirqat area. Iraq J Geogr Inf Syst 4: 117-127.

15. Ramakrishnan D, Bandyopadhyay A, Kusuma KN (2009) SCS-CN and GISbased approach for identifying potential water harvesting sites in the Kall Watershed, Mahi River Basin. India J Earth Syst Sci 118: 355-368.

16. Clark J (1998) Putting water in its place: A perspective on GIS in hydrology and water. Hydrol Process 12: 823-834.

17. Kumar M, Agarwal A, Bali R (2009) Delineation of potential sites for water harvesting structures using remote sensing and GIS. Journal of the Indian Society of Remote Sensing 36: 323-334.

18. Youssef A, Pradhan B, Sefry S (2014) Remote sensing-based studies coupled with field data reveal urgent solutions to avert the risk of flash floods in the Wad Qus (east of Jeddah) Kingdom of Saudi Arabia. Natural Hazards.

19. Rahimi S, Gholami Sefidkouhi MA, Raeini-Sarjaz M, Valipour M (2014) Estimation of actual evapotranspiration by using MODIS images (a case study: Tajan catchment). Arch Agron Soil Sci.

20. David T (2006) The Rational Method. Civil Engineering Department, Texas Tech University, 1-7

21. Deng Y, Wilsonj J, Bauer O (2007) DEM resolution dependencies of terrain attributes across a landscape. Int J Georg Info Sci 21: 187-213. 